\title{
EDUCATIONAL
}

TECHNOLOGY

\section{Twenty five years of educational radio: VL2UV and its world}

\author{
John G Hedberg \\ Coordinator of Continuing Education \\ University of New South Wales
}

Twenty five years ago, VL2UV, the first campus-based educational radio station in the southern hemisphere began operating from the University of New South Wales, and in June this year we quietly stopped regular broadcasting. The only response was a sympathy card sent by one of the other technical units on campus, who felt the technical loss if nothing else. Over the past few years those of us in the educational broadcasting area have found times increasingly difficult to maintain high standards of production output and a facility that is really in demand by our audience. It thus is an appropriate time with general budget uncertainty and unclear directions to examine the role of educational radio.

\section{History of VL2UV}

The early days of VL2UV were exciting and without significant competition. It started from an initial submission to the Australian Universities Commission by the Vice Chancellor for a special Commonwealth Grant of $£ \mathrm{~A} 13,500$ to equip an educational radio station at the University. Part of the submission (Broadbent, 1982, p. 127-128) read:

Educational broadcasting by its very nature and applications falls between the correspondence course and the typical university lecture course to a large class; it could be argued that for teaching certain subject matter it is superior to both. A recent survey by the University of Wisconsin showed that correspondence students do at least as well as classroom students as far as assimilation of subject matter is concerned. The same factors that produce this application by correspondence students should apply to students in the type of 
extension radio broadcast course dealt with below. (In this type of course it is important that material, similar in nature to correspondence material, is supplied to the student to provide the visual link with the lecturer.)

An added consideration that appears to support the establishment of extension radio in the University of New South Wales is the shortage of accommodation in evening during term time, particularly for large classes, at Kensington. Extension radio is cheap and requires negligible accommodation irrespective of size of class.

The nature of the Proposed Radio Courses:

Courses of this nature could with advantage be offered to:

a. adult students requiring special courses. The range here is from the fairly high level (subject matter) course to the course supplying entertainment plus;

b. adult students requiring professional refresher courses;

c. country students requiring certain undergraduate subjects, for credit if later found desirable:

d. adult graduates requiring graduate courses;

e. high school students who are required to make good certain university entrance deficiencies.

The students could participate as:

i. individual students in their home,

ii. a group sharing a receiver; this arrangement would enable helpful group discussion on the subject matter;

iii. a group under a tutor at an Extension Centre.

Estimated Cost of a Radio Station

1. Transmitter + standby equipment

2. Audio equipment control console

3. Audio equipment editing console

4. Monitoring receivers and equipment

5. Two soundproof studios (sprung rooms) 3000

$25^{\prime} \times 25^{\prime}$ at $£ 500 / 100 \mathrm{sq} \mathrm{ft}$

6. Radio mast $100 \mathrm{ft}$ structure (including erection) 3000

7. Studio equipment 
A positive response created the station VL2UV on 1750 kilohertz. The words "if later found desirable" were added by the less encouraging members of the university who saw the project as a potential threat to their jobs. The original licence was authorised by the Postmaster General's Department in April 1961 with a maximum aerial power of 300 watts. The provision of the licence was from the start a disadvantage: all receivers had to be modified to receive the station, the power was only $0.6 \%$ of the power of the $\mathrm{ABC}$ stations operating at the time, and no music could be played over the station. This last restriction was later lifted.

Courses of an average length of 15 hours could be delivered right into students' own homes. Despite the magic of television, the apparent convenience of this mode of delivery became a well supported enterprise. In 1963, two years after the station began operations, enrolments were at 748 persons, four years later in 1967, they had reached a peak of 2045 (Hukins \& Hedberg, 1986). From these glorious days, enrolments slowly declined during the 1970s to hover around 1500 enrolments annually. More recently, especially when pitted against audiocassette tapes, enrolments have declined to 10 to 20 people per course (see Figure 1).

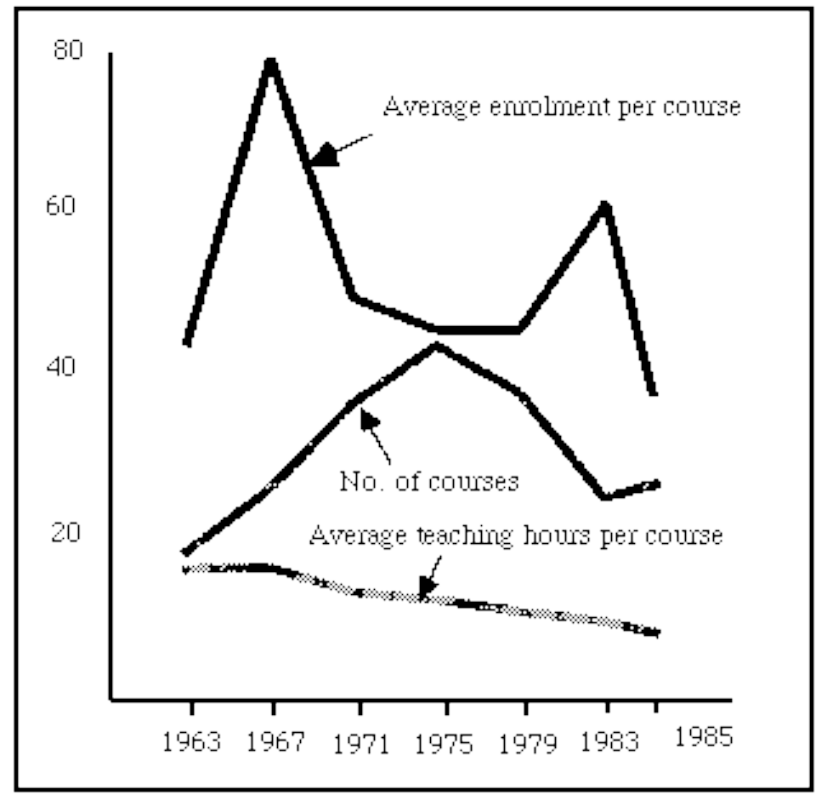

Figure 1: Courses broadcast over VL2UV 1963-1985

(Hukins \& Hedberg, 1986, p3)

This story has been reflected by another early starter in the educational radio stakes, $5 \mathrm{UV}$ run by the then Department of Adult Education at the 
University of Adelaide. Writing in 1977 about the first five years of the stations' life. Lindsay and McLeod (1977, p 23) described the initial enrolment in 1972 of 1113 and two years later it had grown to 2032. By 1981, when the station was fighting a battle for its existence during a University review of the station operations, the enrolments had declined to 428 persons (Bourke, $1982 \mathrm{p} 99$ ) in the earlier report, Lindsay and McLeod had claimed that the station was hampered by being located at the "wrong" end of the AM band - the end at which no listener was ever "knob twiddling" aimlessly and the end that suffered from significant interference in reception. This was later rectified by a change that brought the frequency into the middle of the band and helped to make the station inescapable for the discerning listener.

It is not sufficient to mourn the loss of enrolment, for this was the early concept for radio in education. Educational Radio or television for that matter was conceived as the delivery of "lectures" by an alternative means. This concept was similar to the traditional concept of adult education, learning to improve oneself. But many things have occurred during the past twenty five years that have had a significant bearing on where radio as an educational means is heading.

If we try to draw a timeline, it is important to note other technological developments which have occurred to make the task more difficult or challenging. Certainly, technological changes have created a more discerning clientele and an audience that has more audio options under their personal control. For instance, the audio cassette became the rage in the early 1970s. By 1974 much of the materials produced for formal instruction on VL2UV could be also purchased as cassette tapes. If you really wanted to listen to the material, it was certainly easier to listen at times that were convenient to you, although you didn't have the same forced schedule which might have helped to keep you on task.

In the early seventies VL2UV experimented with talk-back and providing supporting seminars to make the courses more involving. This experiment was moderately successful, and depended upon the size of the enrolled listening audience. There was also a focus upon the professions by the University of New South Wales station by way of reaction against a document suggesting that university funds should not be used for general courses only the postgraduate variety. This in effect became the modus operandi for VL2UV for the rest of its life.

Early in its life the second runner in the educational radio stakes $5 \mathrm{UV}$ had created a less restrictive view of adult education and the promotion of that view led to some restrictive tussles with the Broadcasting Control Board. One restriction placed on both licences was that the stations were not allowed to use music, which did seem a little silly if you were talking 
about the great composers. This little constraint was the element in the 5UV tussle. 5UV also led the way with student and volunteer broadcasters which has become the norm for most public stations.

Two events occurred closely in time. The first was a political event, a review of the broadcasting priorities by the newly elected Whitlam government, and the second was changing the broadcasting technology. In July of 1974. a major gathering of those who were interested in the use of proposed new frequency allocations and the possibility of beginning broadcasts in frequency modulation was held in Sydney. This conference, hastily convened by the Department of the Media, saw the first combined public statement on public radio broadcasting and was the beginning of a series of newer public stations. The issues of hot debate were: Educational/Campus stations, Special groups such as ethnic broadcasters, music broadcasters, women, adult education and the technical issue AM versus FM. (There was a slight hiccup in that the Australian Broadcasting Control Board - the regulatory body of the time - had a proposal to place the FM band somewhere in the UHF television frequencies which would make Australia unique in the world and have to make special and, at that time, untested FM receivers for this unique band. Fortunately, sense prevailed and the standard band as used throughout the world was agreed upon, and a number of television stations had to move slightly to make way).

\section{The new breed of stations - one each and everywhere}

Following the review of the broadcasting band and knowing that there was space for other groups to get into the act, in their last days, the Whitlam government offered to many educational institutions the chance to take up a broadcasting licence. Thus from the middle seventies, we see the increase in campus and community stations. These stations each created their own policy and reasons for existence. At this time, I was asked to get the radio station of the Royal Melbourne Institute of Technology off the ground and with an enthusiastic group of student producers, we started broadcasting. The transmitters for these early enterprises were not always new. 3RRR operated with a converted television transmitter donated to the Institute by Channel 7 in Melbourne. Eventually these stations, run largely by volunteers, had to find funding to cover the costs of increasing full time staff. The uncertainty of college administrators about what would go to air meant that libel insurance was the order of the day (especially as you couldn't trust the students!). While I feel that these fears were largely unfounded, they did mean that many stations never really received sufficient funding to make the initial capital investment worthwhile. 
The other political event of this period was the beginning of the tertiary education cutbacks under the Fraser government, a move that meant that fledgling stations had to look elsewhere for funding. In time, some became consortia to cover costs, and certainly most today use volunteers and feepaying access groups to cover the cost of broadcasting.

By way of a side comment, the middle seventies was also the period in which a number of major educational radio projects around the developing world were assessed (see for example, Jamison, Klees and Wells, 1978; Schramm, 1977). The economics and the prognostications were mixed, and while some of the evaluations showed that radio was a cheap medium it was still cheaper to provide a teacher, especially if the costs were considered "add on" to the existing budget. The quality argument was not an economic consideration.

The late seventies saw the VHS videocassette make a major breakthrough into the domestic market. This meant that radio had one more technology against which to compete.

\section{The educational programming response}

Programming on these new "educational" stations has followed diverse paths, some included the focus of special groups, such as "old time radio" emphasised by $6 \mathrm{NR}$ in Perth. While others have tried to support Australian Music and the training of students of Journalism and audio broadcasting media.

Those that have tried to run formal courses which are self supporting are finding it increasingly difficult. The alternative delivery technologies make the task more effective and also more complex. When producing instructional materials for audiocassette markets, it is possible to adopt more varied formats than audio broadcasting since there is the magic ingredient - student control over the presentation. Radio has countered by increasing talk-back and making the broadcasting component fit into criteria such as immediacy and responsiveness. Realistically, this form of response is still only required to supplement direct instruction and personal learning achieved by students working through materials independently. In this there are the seeds of some new roles for broadcasting. The real survivors are those people who break the rules and attempt to combine the real needs of the audience with the widest application of the technology.

Most of the newer stations did not start with the formal course basis and they have developed new and varied formats for pursuing educational ideals. Magazine programs and special "network" contributory programs provide a much needed source of educational material relatively cheaply. 
All stations in the public area really do rely on the good will and commitment of individuals to keep their program going. The definition of educational has also been expanded to include informational programming as well as formal courses. The new format of the $A B C$ National Adult Education radio has moved into this area and some of their series are the current exponents of the formal course over the radio. However the $\mathrm{ABC}$ also limit the full scale application of formal courses in that they must be populist and each program an interesting entity.

Other ideas have been used by many educational stations to ensure a committed and supportive audience. Subscriptions have been popular both here and in other countries, notably the United States. 5UV pioneered this style of support in Australia to great advantage. This method of gaining support is very diffuse but when managed well, it can be a tremendous source of station support. Unfortunately, most of the time subscribers are seen as convenient ways of grabbing a few dollars with little care and feeding being provided in return. This type of support and proper marketing could result in real gains and help community based stations fulfil an important role. Some thoughts under this category include: the tracing of subscriptions over the years, trying to determine when they lapse and why. close involvement with a station that delivers a range of products one of which might be publications and formal courses in areas that are not just the traditional academic ones. What about the idea of relaxation over radio, massage with a few printed diagrams, in depth background briefings on foreign and domestic affairs, readings of novels, and catering to specific groups with educational needs.

Most public broadcasters use access groups to "fill" their programming and also to help defray some of their operating costs. These groups provide an important service to special groups in a way that is not met by any other general broadcaster, although the structure of the station image can be more difficult with many disparate groups following each other. The content of these programs is mainly that of information and cultural traditions of the particular group.

One of the features of programming in the public broadcasting station has been the commitment to training about radio and to providing experience in professional broadcasting. Many campus stations allow trainee journalists to prepare topical material under realistic time constraints and pressure. Training has also been provided for other special groups: access groups, ethnic broadcasters, aboriginal groups and so on, who otherwise would have had little access to such training. The commercial stations don't like someone learning basic techniques in the middle of prime time. This has probably been the most successful aspect of radio as an educational means and one I foresee as important in the future. 


\section{What's left of the great dreams?}

Radio has had to deal with a series of technological challenges from television, and other aural delivery means. The technology of radio broadcasting itself has changed over the past ten years so that stereo is now commonplace both on the AM and FM bands and satellites can provide a wider area coverage and the possibility of networked programming. The technological developments have required station management to keep upgrading station equipment and recording quality and have transferred the costs from the somewhat hidden capital area into direct running costs that must be paid each year. While the costs for radio equipment are still a fraction of television equipment, they still comprise a major part of the station's annual budget.

At the same time a series of political and administrative changes in the way many stations have been and continue to be funded, require creative and entrepreneurial skill to keep the effort afloat. In this context what are the possibilities for radio as an educational means?

General beliefs in adult education ideals seem to be now only the province of the $\mathrm{ABC}$, who can operate without recouping all their operating costs. Recent reports (Johnson, 1986) have indicated that Universities might have to recoup even more of the continuing education operating budgets from fees charged. This will signal the death of formal courses if other merchandising such as notes and cassettes do not cover the production expenses.

Production values in programming, trying a mix of materials some on cassette, some broadcast may mean one solution to educational use of radio. If the main part of instruction is given by printed materials and audiocassette then the radio can be used to focus on the feedback required by students learning at a distance. This type of experiment has been tried two ways, one using 2SER-FM to University of New England students in Sydney and the other a FM subcarrier experiment on 6UVS-FM in Perth. Both these two approaches have been successful and both link into formal distance learning courses - a point that I believe we should examine more closely if we are to cover the costs by showing we can use the medium in cost effective ways. I feel that there are great possibilities if areas, such as the TAFE distance learning groups link into this mode of teaching. The call for courses is greater from this group than the traditional tertiary institutions offering broadcasting to their students. In the west of Sydney, I believe that the more successful outreach groups from TAFE could easily combine to produce to provide some support for parents who are constrained by young children to their homes and who want some contact with others in constructive personal development experiences. To achieve this, some innovative approaches to combining attended, broadcast and 
audiocassette delivery to meet the needs and the objectives of an activity. It is always easier to distribute everything through one medium and we need to really focus on the skills and performances required before we try to push every idea into the same mould.

Most of the educational applications do not draw large formal audiences. However, if the distribution is over a sufficiently wide enough area, especially those areas poorly served by other courses, we might yet see a use of radio as an educational gathering tool. Certainly it can work to bring isolated people and groups together. It might be that the $\mathrm{ABC}$ approach of networking might also need to be considered as a normal method of educational programming by other groups of stations. The series "Open Mind" is the beginning of such an effort Direct satellite broadcasting might be the technological way to get to isolated people but the costs for local dish receivers will make the purchaser think more of television than radio. However, the use of satellites might be to reach a wider if still specialised audience, professional groups wanting instant information might find it sufficiently valuable that professional associations will pay for the access.

Ease of access to the station is not improved by moving onto a subcarrier FM broadcast. This technology while ideal for special groups still requires special receivers and an informed and committed audience (both difficult commodities unless you are a select special group). This approach is not much better than having a station of the end of the AM band - a difficulty which plagued 5UV and continues to limit VL2UV. If we are to reach a general audience then special receivers will only limit the access to the audience.

The changes in the $\mathrm{ABC}$ towards educational radio I feel are the best moves in years, even though it increases the competition amongst educational broadcasters. The focus for $\mathrm{ABC}$ Adult Education radio is rightly placed on the audience which was not served with beautiful music and incessant chatter about the events of the day. At the same time this provides educational broadcasters will a challenge - we have rely more on the resources of the institutions from which we draw our support. This might mean building on the current push for marketing of educational services or traditional beliefs of access to courses and information which were not available to a person when they left school.

\section{Directions}

There are many positive advantages of radio as an educational means. It is possible to devise a list as part of the credo by which each enthusiast for this medium learns the standard applications and production styles of the medium. This is great for beginners but we are no longer beginners. 
Experiments and creativity are to be more prized than ever, and the limits of radio should be clearly seen from perspectives, such as the ease of access for the audience to the station, the quality and timeliness of the presentation, the need for immediacy and feedback, the competition from any other print, aural and even visual medium. it is important not to force everything into the radio sausage, but rather mix and match until each medium is reaching its audience effectively. It is very easy to think something produced well for radio cannot be bettered, but think of the possibility of interactive lessons including computer generated speech, or self- study materials produced for audiocassette listening; these are more ideal flexible methods of presenting aural information. If educational radio is to make an impact then it must realise that these technology options are in competition not to mention the preference for attended courses where for $\$ 45$ you can talk quietly to a teacher and get even better help!

Program exchange, the recognition of courses from one institution by others so that credit can be obtained from either, the possibilities of knowledge networks, all could make substantial contributions to the viability of radio as a delivery medium. With one "educational" station in each listening area, joint courses and the acceptance of completion of them as credits towards a certificate, diploma or degree would reduce automatically production costs and provide a market for our output. The final crunch must be that we have to establish a base of support within the existing structures and institutions, so that our educational programming can achieve all those lofty ideals we set years ago. We have to look at merchandising, and creatively using the subscribers that believe that the radio link is an effective means for keeping them in touch.

For stations like VL2UV, there was a limited future. Those stations on the regular band and those which diversified earlier into a wider range of program and support are likely to move into the next 25 years. The terrestrial telecommunications network can compete effectively by employing teleconferencing for special groups. The role of a specialised broadcast facility is difficult to foresee, certainly there is the enthusiasm for some activity but little when compared with the support for new developments in video and computing. If the little clause "if later found desirable" had never been inserted in the initial proposal, perhaps we might have seen a delivery system for formal tertiary education that might have pre-dated the Open University which seems to have largely stolen the credit for the pioneering work of Australian educational stations.

\section{Note}

This paper was based upon a talk first given to the Educational Radio Conference, Public Broadcasting Association of Australia, Sydney, August 9th to 10th, 1986. 


\section{References}

Bourke, P. F. (Chairman) (1982). Review of the Department of Continuing Education: Report of the Committee of Review. Adelaide: University of Adelaide.

Broadbent, D. E. (1982). Radio and television universities in New South Wales. In D. C. B. Teather (Ed), Towards the Community University: Case Studies of Innovation and Community Service. London: Kogan Page, pp.123-142.

Department of the Media (1974). Papers presented to Public Radio Broadcasting in Australia Conference. Held in Sydney, July 3rd to 4th, 1974.

Hukins, A. A. \& Hedberg, J. G. (1986). Annual Report on Continuing Education. 1985. Kensington: Continuing Education Support Unit, University of New South Wales.

Lindsay, E. \& McLeod, G. (1977). 5UV the first years. Adelaide: Department of Adult Education. University of Adelaide.

Jamison, D. T., Klees, S. J. \& Wells, S. J. (1978). The costs of educational media: Guidelines for planning and evaluation. Beverley Hills. CA: SAGE.

Johnson, R. (1986). Report on continuing education. Canberra: Commonwealth Tertiary Education Commission.

Schramm, W. (1977). Big media, little media. Beverley Hills, CA: SAGE.

Please cite as: Hedberg, J. G. (1986). Twenty five years of educational radio: VL2UV and its world. Australian Journal of Educational Technology, 2(2), 7484. http: / / www.ascilite.org.au/ajet/ ajet2/hedberg.html 